\title{
3-Port incisionless laparoscopic surgery for rectal cancer with a transrectal assistance
}

\author{
Lin Zhang, Guohu Zhang, Peihong Wang, Yonghua Wang, Yaning Song, Hong Zou, \\ Lijun Tang ${ }^{*}$ \\ Center of General Surgery, Chengdu General Hospital of Chengdu Military Area Command, Chengdu, China; \\ *Corresponding Author: whjtlj99@hotmail.com
}

Received 25 July 2013; revised 26 August 2013; accepted 8 September 2013

Copyright (c) 2013 Lin Zhang et al. This is an open access article distributed under the Creative Commons Attribution License, which permits unrestricted use, distribution, and reproduction in any medium, provided the original work is properly cited.

\begin{abstract}
Introduction: To present the initial experience of 3-port incisionless laparoscopic surgery for rectal cancer with a transrectal assistance by using a toothed oval clamp. Case Presentation: One patient received 3-port incisionless laparoscopic surgery for rectal cancer with a transrectal assistance by using a toothed oval clamp. Better direct vision and exposure could be acquired for performing laparoscopic surgical procedure, avoiding additional port inserted. Using this procedure, with strictly adhering to the principles of laparoscopic colectomy and oncological procedure, along with the specimen exteriorized via recta, transacted and a stapled anastomosis performed, no incision can be achieved at the end of an operation. The operative time was $\mathbf{1 8 0}$ minutes. The estimated blood loss in the course of an operation was $80 \mathrm{ml}$. The patient recovered quickly after surgery, with no post-operative pain and no incision. The patient was dischanged home on the 6th postoperative day. Conclusions: With a transrectal assistance by using a toothed oval clamp, 3-port laparoscopic surgery for rectal cancer could be achieved without no incision at the end of the operation, the same as NOTES. It is enormously advantageous to the patient and suitable for application in developing countries, especially in a rural area.
\end{abstract}

Keywords: Laparoscopic Surgery; Incisionless; Rectal Cancer; Transrectal; Assistance

\section{INTRODUCTION}

In recent years, laparoscopic surgeries have been widely accepted as a treatment of colon diseases, includ- ing colon cancer [1-3]. The short term benefit of the laparoscopic approach in colorectal surgery is obvious, namely, faster postoperative recovery, improved postoperative pain control, reduced pulmonary dysfunction, and shorter hospitalization [4-6].

In order to further improve upon the results of multiport laparoscopic colectomies (LACs), efforts have been made to further reduce the trauma caused by incisions, even in a minimum number of port sites inserted with trocars used. Now natural orifice transluminal endoscopic surgery (NOTES) provides the potential for performance of scarless operations. In 2007, Whiteford et al. described the first transanal NOTES radical sigmoidectomy in human cadavers [7]. However, the progress continues to be hampered by always needing for expensive specialized equipment as well as safety concerns regarding NOTES translumenal access, particularly regarding access closure [8]. To some extent, it has hindered the widespread acceptance of this approach.

Since 2008, when single-incision laparoscopic colectomy (SILC) was first introduced, the number of relevant publications has been increasing yearly. In comparison to multiport laparoscopic colectomy, the potential advantages of SILS are thought to be improved cosmesis as well as incisional and/or parietal pain and avoidance of port site-related complications [9]. But expensive proprietary equipment and additional incisions are needed for retrieval of the specimen.

In this paper, we introduce a new surgical procedure of 3-port incisionless laparoscopic surgery for rectal cancer with a transrectal assistance by using a toothed oval clamp.

\section{CASE REPORT}

A 38-year-old married female presented to her local doctor with bloody stools. Than the patient was referred to our hospital for the reason that a crater lesion of $\sim 30$ $\mathrm{mm}$ in diameter and $8 \mathrm{~cm}$ from the anal verge had been 
found in the middle rectum by colonoscopy. The biopsy outcome confirmed rectal adenocarcinoma. The patient's past history and laboratory test results were not contributory.

The potential risks and benefits of the operation were discussed with the patient, who gave informed consent. All of the principles of laparoscopic colectomy and oncological procedure were strictly adhered to.

The patient was placed in the lithotomy position. three ports (Johnson \& Johnson, USA) were used, with placement in the left upper for $5 \mathrm{~mm}$ trocar, right upper for 12 mm trocar which was later used as a drain site, umbilicum upper for $12 \mathrm{~mm}$ trocar and for $30^{\circ}$-angled scopes (Olympus, Japan). At the beginning of procedure, the operator was located in the two legs of the patient, in order to visualize abdominal organs in line with the $30^{\circ}$ angled scopes without the need for retroflexion. En-bloc resection and mobilization of the sigmoid colon and its mesentery proceeded cephalad along the avascular plane. The inferior mesenteric artery (IMA) was highly dissected and staple divided (Clips, Johnson \& Johnson MEDICAL GmbH, USA) (Figure 1). After the adequate length of the sigmoid colon was carefully preserved for anastomosis, the colon was subsequently obtained to introduce an endoscopic linear stapler (Johnson \& Johnson, USA) into the peritoneal cavity and divided followed by introducing the anvil of the circular stapler (Johnson \& Johnson, USA) into the proximal colon via transrectum.

Following this, the operator changed to located in the left position of the patient, in order to perform procedure in line with the field of vision of the $30^{\circ}$-angled scopes.

The left and right ureter were identified, and the presacral plane was carefully caudally developed with preservation of the autonomic nerve fibers using the technique of sharp total mesorectal excition with a transrectal assistance by using toothed oval clamp (Figure 2). Once the peritoneal reflection was reached, the colon was then pulled out through the rectum, transected and a intracorporeally stapled colorectal anastomosis performed with the circular stapler (Johnson \& Johnson, USA) used (Figure 3). A drainage tube was posited upper anastomotic line via transrectum, avoiding temporary diverting loop ileostomy and anastomotic leakage (Figure 4).

The operative time was 180 minutes. The estimated blood loss in the course of operation was $80 \mathrm{ml}$. The patient recovered quickly after surgery, with no postoperative pain and no insicion. On postoperative day 3 the patient had completely resumed total gastrointestinal function and had her first flatus. The blood loss of drainage tube was about 30 - $50 \mathrm{ml}$ per day and was pulled out on postoperative day 4 . The patient was dischanged home on postoperative day 6. Pathology re-

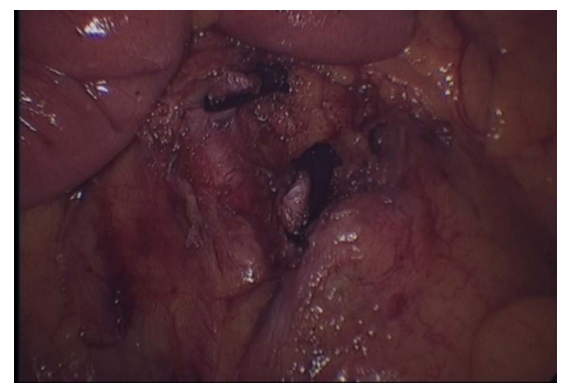

Figure 1. The inferior mesenteric artery (IMA) was highly dissected and staple divided.

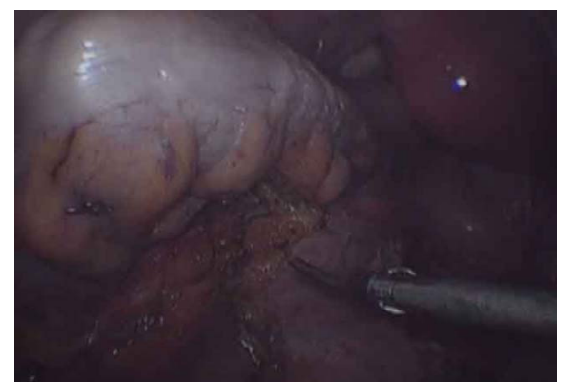

Figure 2. Excision of mesorectum along the prescaral plane with exposure by using transrectal toothed oval clamp.

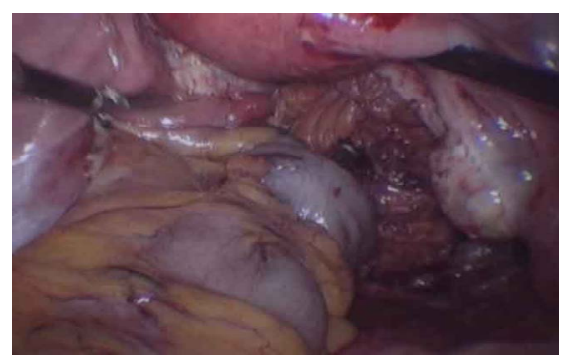

Figure 3. View of intracorporeally coloanal anastomosis performed between the proximal sigmoid colon and distal anorectal cuff.

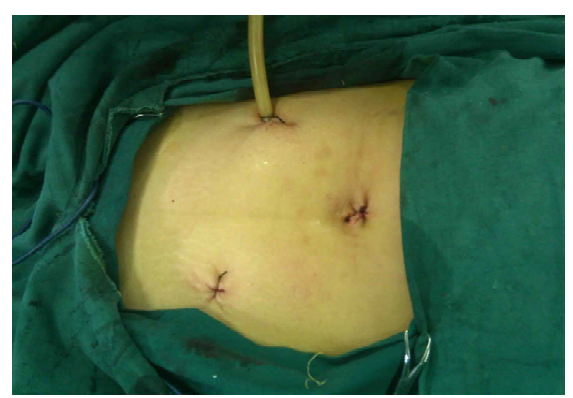

Figure 4. 3-port used after incisionless laparoscopic rectal operation, one of which was used as a drain site.

vealed an intact mesorectum with 3 out of 12 retrieved lymph nodes positive for adenocarcinoma (pT3N1). Mar- 
gins were free of tumor.

\section{DISCUSSION}

Although many large randomized trials with the laparoscopic approach in colon cancer had demonstrated equivalent oncologic efficacy with similar overall survival, disease-free survival and local and distant recurrences [10-12], the relevant data of large randomized trials with the laparoscopic approach in rectal cohort is scarce, hampering its widely accepted.

Overall laparoscopic rectal resection for malignancy is technically more demanding in that concerns about nerve preservation, complete total mesorectal excision, and adequate lymph node yield are still unsettled in this setting. But the remarkable magnified view provided by the monitor of laparoscopic operation system has become more advantageous and fascinating and enables safe and accurate manipulation at sites such as the deep pelvic floor, lower bladder, posterior surface of the prostate and anal region, where visualization is difficult to achieve during open surgery and manipulation is usually carried out under nearly blind conditions [13].

In order to further improve upon the results of LACs, efforts have been made to further reduce the trauma caused by incisions, even in a minimum number of port site inserted with trocars used. This results in a paradox. on one hand, both operator and patient persue scarless or minor insicions; on the other hand, with reduction number of port site, exposure of operating site should be more difficult for performing adequately surgical procedure. So we put forward a useful laparoscopic assisting approach with a transrectal assistance by using toothed oval clamp.

In our opinion, a new transrectal laparoscopic assisting approach offers multiple advantages: 1) with respect to laparoscopic surgery for rectal cancer, the sharp angle of the sacral promontory and narrow pelvis hindered the proximal dissection of rectal wall and its attached mesentery. To overcome those anatomic constraints, exposure turned out to be more important. Based on our early experience, with a transrectal assistance by using toothed oval clamp performed by second assistant, operator could acquire better direct vision and exposure for performing laparoscopic surgical procedure, avoiding additional port inserted; 2) Patients, both male and female, independent of age and body shape, usually dislike scars, not only for cosmetic reasons but because scars indicate they have undergone treatment before. This resulted in NOTES, eliminating the incision through the abdominal wall and using natural orifices, meeting the aspirations of the patients and surgeons [14]. But in the level of LACs, minor incision always needed. Using our above-mentioned procedure, along with the specimen exteriorized via transrectal, transacted and a stapled anastomosis per- formed, incisionless can be achieved at the end of operation, same as NOTES; 3) Our new transrectal laparoscopic assisting device is much cheaper than instrument of other minimally invasive surgeries in that it is a simple device whose cost is approximately 50 USD. So it is suitable for application in developing countries, especially in a rural area.

Nevertheless, we have to refer some caveats emerged in our initially experience with this technique. Firstly, strict selection of patients for this approach include those with biopsy proven resectable rectal malignancy located 4 - $12 \mathrm{~cm}$ from anal verge who are otherwise eligible to undergo standard open or laparoscopic low anterior resection with temporary diverting stoma. Meanwhile tumors must be preoperatively staged as node negative, $\mathrm{T} 1$, T2 or T3 based on pelvic MRI with no evidence of metastasis on staging CT scans. Secondly, lesions of eligible patients which causing no more than $50 \%$ stenosis of the lumen, as well as better mechanical bowel preparation, could ensure a satisfied operation outcome, avoiding temporary diverting loop ileostomy and anastomotic leakage.

\section{CONCLUSION}

On the basis of our preliminary experience, we believe that with a transrectal assistance by using a toothed oval clamp, 3-port laparoscopic surgery for rectal cancer can be done without an incision at the end of the operation, same as NOTES. With this useful technique, made from commonly used and relatively inexpensive surgical equipment, avoiding long and complex learning curves, operator could acquire much more exposure, assistance during performing surgical procedure. Above all, it is suitable for application in developing countries, especially in a rural area.

\section{REFERENCES}

[1] Bonjer, H.J., Hop, W.C., Nelson, H., Sargent, D.J., Lacy, A.M., Castells, A., Guillou, P.J., Thorpe, H., Brown, J., Delgado, S., Kuhrij, E., Haglind, E. and Påhlman, L. (2007) Transatlantic laparoscopically assisted vs open colectomy trials study group. Laparoscopically assisted vs open colectomy for colon cancer: A meta-analysis. Archives of Surgery, 142, 298-303.

http://dx.doi.org/10.1001/archsurg.142.3.298

[2] Nelson, H., Sargent, D.J., Wieand, H.S., Fleshman, J., Anvari, M., Stryker, S.J., Beart Jr., R.W., Hellinger, M., Flanagan Jr., R., Peters, W. and Ota, D. (2004) A comparison of laparoscopically assisted and open colectomy for colon cancer. The New England Journal of Medicine, 350, 2050-2059. http://dx.doi.org/10.1056/NEJMoa032651

[3] Laurent, C., Leblanc, F., Bretagnol, F., Capdepont, M. and Rullier, E. (2008) Long-term wound advantages of 
the laparoscopic approach in rectal cancer. British Journal of Surgery, 95, 903-908.

http://dx.doi.org/10.1002/bjs.6134

[4] Wexner, S.D., Reissman, P., Pfeifer, J., Bernstein, M. and Geron, N. (1996) Laparoscopic colorectal surgery: Analysis of 140 cases. Surgical Endoscopy, 10, 133-136. http://dx.doi.org/10.1007/BF00188358

[5] Okabayashi, K., Hasegawa, H., Watanabe, M., Nishibori, H., Ishii, Y., Hibi, T. and Kitajima, M. (2007) Indications for laparoscopic surgery for Crohn's disease using the Vienna classification. Colorectal Disease, 9, 825-829. http://dx.doi.org/10.1111/j.1463-1318.2007.01294.x

[6] Hildebrandt, U., Kessler, K., Plusczyk, T., Pistorius, G., Vollmar, B. and Menger, M.D. (2003) Comparison of surgical stress between laparoscopic and open colonic resections. Surgical Endoscopy and Other Interventional Techniques, 17, 242-246. http://dx.doi.org/10.1007/s00464-001-9148-9

[7] Whiteford, M.H., Denk, P.M. and Swanstrom, L.L. (2007) Feasibility of radical sigmoid colectomy performed as natural orifice translumenal endoscopic surgery (NOTES) using transanal endoscopic microsurgery. Surgical Endoscopy and Other Interventional Techniques, 21, 18701874. http://dx.doi.org/10.1007/s00464-007-9552-x

[8] Sylla, P. (2010) Current experience and future directions of completely NOTES colorectal resection. World Journal of Gastrointestinal Surgery, 2, 193-198. http://dx.doi.org/10.4240/wjgs.v2.i6.193

[9] Rieger, N.A. and Lam, F.F. (2010) Single-incision laparoscopically assisted colectomy using standard laparoscopic instrumentation. Surgical Endoscopy and Other Interventional Techniques, 24, 888-890. http://dx.doi.org/10.1007/s00464-009-0683-0
[10] Fleshman, J., Sargent, D.J., Green, E., Anvari, M., Stryker, S.J., Beart Jr., R.W., Hellinger, M., Flanagan Jr., R., Peters, W. and Nelson, H. (2007) Laparoscopic colectomy for cancer is not inferior to open surgery based on 5-year data from the COST study group trial. Annals of Surgery, 246, 655-662. http://dx.doi.org/10.1097/SLA.0b013e318155a762

[11] Jayne, D.G., Thorpe, H.C., Copeland, J., Quirke, P., Brown, J.M. and Guillou, P.J. (2010) Five-year follow-up of the medical research council CLASICC trial of laparoscopically assisted versus open surgery for colorectal cancer. British Journal of Surgery, 97, 1638-1645. http://dx.doi.org/10.1002/bjs.7160

[12] Leung, K.L., Kwok, S.P., Lam, S.C., Lee, J.F., Yiu, R.Y., Ng, S.S., Lai, P.B. and Lau, W.Y. (2004) Laparoscopic resection of rectosigmoid carcinoma: Prospective randomized trial. The Lancet, 363, 1187-1192. http://dx.doi.org/10.1016/S0140-6736(04)15947-3

[13] Mukai, M., Sekido, Y., Fukumitsu, H., Izumi, H., Hoshikawa, T., Tajima, T., Tobita, K., Sadahiro, S., Yasuda, S. and Ogoshi, K. (2011) Anal function-preserving subtotal intersphincteric resection/partial external sphincteric resection with hybrid 2-port hand-assisted laparoscopic surgery (Mukai's operation) for very low stage I rectal cancer: A case report. Oncology Letters, 2, 801-805. http://dx.doi.org/10.3892/ol.2011.327

[14] Marescaux, J., Dallemagne, B., Perretta, S., Wattiez, A., Mutter, D. and Coumaros, D. (2007) Surgery without scars: Report of transluminal cholecystectomy in a human being. Archives of Surgery, 142, 823-827. http://dx.doi.org/10.1001/archsurg.142.9.823 